\title{
AUTO-ORGANIZAÇÃO E BIOÉTICA: O PROBLEMA DA SUSTENTABILIDADE
}

Alfredo Pereira Junior

Professor Doutor do Departamento de Educação do Instituto de Biociências da UNESP - Campus de Botucatu, e docente no Programa de Pós Graduação em Filosofia da Faculdade de Filosofia e Ciências - UNESP - Campus de Marília. E-mail: alfredo.pereira@unesp.br

Valdir Gonzalez Paixão Junior

Professor Doutor do Departamento de Educação do Instituto de Biociências da UNESP - Campus de Botucatu. Doutor em Sociologia pela UNESP - Araraquara. Coordenador de área do PIBID, no Subprojeto do Curso de Licenciatura em Ciências Biológicas. E-mail: valdirpaixao@ibb.unesp.com.br

\section{RESUMO}

No Século XXI, ao constatar o impacto ambiental das ações humanas potencializadas pela tecnociência, a comunidade científica tem se preocupado em identificar condutas destrutivas e construtivas frente ao processo de vida terrestre, formulando então o Problema da Sustentabilidade. Para a Bioética, esta reflexão propicia a oportunidade de proposição de novas práticas sociais capazes de garantir a continuidade da vida no ambiente terrestre. Argumentamos que estas novas práticas requerem, além de processos auto-organizativos característicos de uma sociedade democrática, a formação de uma Consciência Bioética, a ser amplamente compartilhada na educação formal, e também utilizando-se a tecnologia da informação. Deste modo, procura-se transformar o processo hetero-organizativo da tecnociência em um processo auto-organizativo no qual a população humana promova práticas sustentáveis.

PALAVRAS-CHAVE: Auto-Organização. Bioética. Consciência. Sustentabilidade. 


\title{
SELF-ORGANIZATION AND BIOETHICS: THE PROBLEM OF SUSTAINABILITY
}

\begin{abstract}
In the 21st century, when the environmental impact of human actions potentiated by technoscience increases, the scientific community has been concerned with identifying destructive and constructive behaviors in relation to the terrestrial life process, thus formulating the problem of sustainability. For Bioethics, this reflection provides the opportunity to propose new social practices capable of guaranteeing the continuity of life in the terrestrial environment. We argue that these new practices require, in addition to selforganizing processes characteristic of a democratic society, the formation of a Bioethical Awareness, to be widely shared in formal education, and also using information technology. In this perspective, we attempt to transform the heteroorganizational process of technoscience into a self-organizing process, in which the human population promotes sustainable practices.
\end{abstract}

KEYWORDS: Self-Organization. Bioethics. Awareness. Sustainability.

\section{INTRODUÇÃO}

O estrondoso progresso da ciência e tecnologia, e sua aplicação a praticamente todos os domínios da vida humana, têm despertado uma série de reflexões éticas a respeito das ações humanas, nas áreas de Saúde (Bioética), Ambiente (Ética Ambiental), Economia e Sociedade (Ética do Comportamento Econômico, Ética Social, Ética do Comportamento Político). Na última década, concomitantemente à percepção ampliada de que estas áreas mantem importantes conexões recíprocas, surgiu a Ética da Sustentabilidade, enfocando o sistema planetário como totalidade integrada, e se propondo a refletir sobre as modalidades de organização da ação humana que possibilitam (ou impossibilitam) que se alcance a meta de sustentabilidade planetária.

Propostas institucionais, bem como publicações sobre este assunto, inclusive um bem elaborado livro-texto (Kibert et al., 2014) e um curso (Smookler, 2010) tem sido divulgadas inicialmente de modo eletrônico (Morris, 2009; Jennings, 2010; Thompson. 2012; Seager, 2013). Encontramos, em pesquisa Google em 01/08/2014, inserindo-se os termos "Sustainability Ethics", e considerando apenas a primeira página de resultados, as seguintes instituições dedicadas ao tema: 
- http://rockethics.psu.edu/climate/sustainability-ethics

- http://www.scu.edu/ethics/practicing/focusareas/environmental ethics/lesson4.html

- http://www.humansandnature.org/

- http://www.ilsr.org/initiatives/the-public-good/

Os autores e instituições acima citados são unânimes ao definirem a ética da sustentabilidade como a conjunção de três grupos de fatores: Justiça Social, Desenvolvimento Econômico e Proteção Ambiental. As interações entre estes fatores e sua conjunção são ilustradas na figura abaixo, extraída do curso ministrado por Smookler (2010). Note-se que as relações diádicas entre os fatores, ensejando aquilo que é suportável ("bearable"), viável ("viable") e igualitário ("equitable") não seriam suficientes para se caracterizar a sustentabilidade, uma vez que se um dos três fatores estiver ausente o sistema encontraria um fator limitante que impossibilitaria que se atingisse a meta da sustentabilidade.

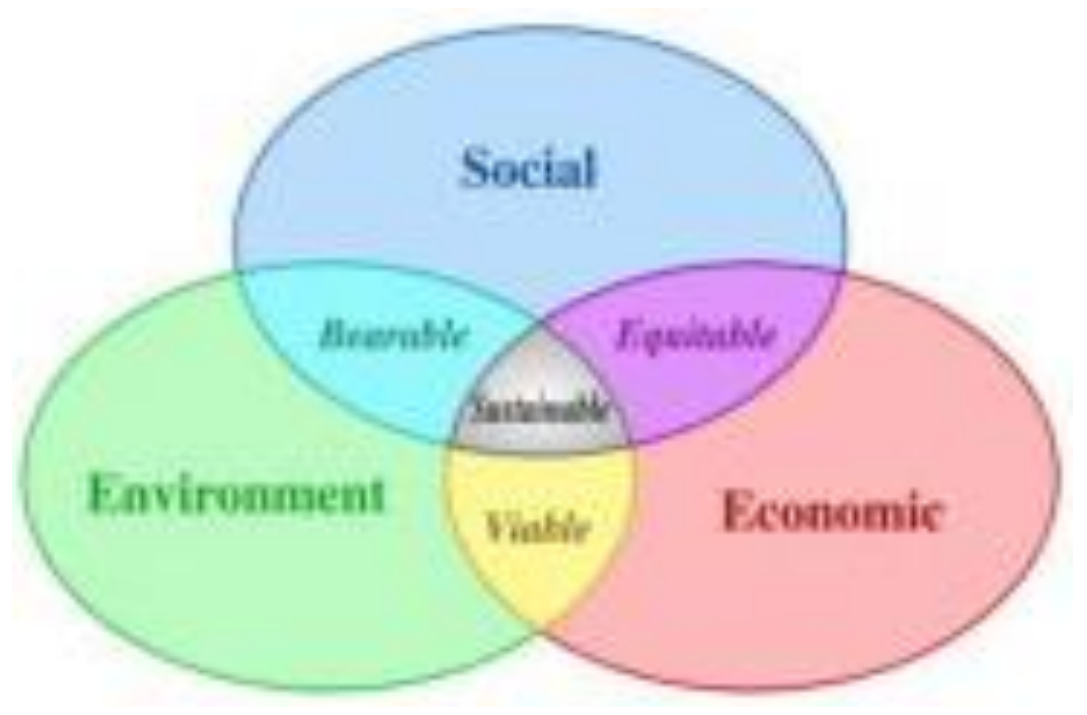

Figura 1 - Dimensões do Desenvolvimento Sustentável.

Fonte: (Smookler, 2010).

Sustentabilidade é um conceito que se refere à dinâmica de um sistema complexo (sobre o conceito de sistema, vide Bresciani Filho e D’Ottaviano, 2000), envolvendo as interações entre os três grupos de fatores apontados. Uma Ética da Sustentabilidade seria então uma reflexão sobre a conduta humana frente a este sistema complexo, partindo-se do pressuposto (já formulado por Baldwin, 1896) de que a consciência humana resulta do processo evolutivo e 
atua sobre este mesmo processo, contribuindo para guiá-lo em direção de metas desejáveis, como a sustentabilidade. Aqui abordamos o Problema da Sustentabilidade, propondo o conceito de Consciência Bioética como guia para elaborações teóricas e práticas efetivas.

\section{ASPECTOS EPISTEMOLÓGICOS}

Juntamente com o surgimento da área interdisciplinar de Ética da Sustentabilidade, cresce a consciência da necessidade de ações práticas voltadas para o enfrentamento de condições adversas concomitantes ao desenvolvimento econômico e tecnológico. Estas condições adversas têm sido vivenciadas pela maioria da população de muitos países, podendose citar como exemplos: o congestionamento habitacional, a poluição urbana, a degradação de florestas, o uso de defensivos tóxicos no campo, os riscos da aplicação da biotecnologia na agricultura e pecuária, as alterações climáticas que comprometem o abastecimento de água e energia, a perda da qualidade nutricional dos alimentos e/ou sua utilização inadequada, o aumento do estresse no trabalho, o uso inadequado de medicamentos, o desemprego crônico, e muitos outros problemas.

É pertinente a participação do filósofo no esforço interdisciplinar voltado à efetivação de práticas sustentáveis, pois este profissional pode contribuir com clarificações conceituais, visando um melhor enfoque dos problemas e auxiliando na busca por soluções científicas e tecnológicas eficazes (ou seja, que atinjam as metas propostas; por exemplo, quanto à redução da emissão de gases que causam o 'efeito estufa') e eficientes (que o façam com relação custo/benefício que seja conveniente; por exemplo, em determinadas regiões do planeta, resolver o problema energético obtendo-se gás de xisto por meio de explosões subterrâneas que comprometem o lençol freático, pode não ser uma solução válida).

No âmbito da filosofia, constatamos que a Ética da Sustentabilidade se insere em diversas subáreas de estudo, como a própria Ética, a Ontologia ou Metafísica e a Epistemologia. A abordagem epistemológica se entrelaça com questões propriamente éticas e ontológicas. Procuramos aqui elucidar o conceito de sustentabilidade, a partir de teorias filosóficas e interdisciplinares sobre Sistemas Auto-Organizados e Evolução, e discutir tal conceito enquanto meta da ação humana, a partir do exemplo bem sucedido da Bioética. Para tal utilizamos:

a) A Teoria da Auto-Organização (Debrun 1996);

b) Os Princípios e Referenciais da Bioética (vide, como introdução ao assunto, Hossne, 
2006) que compõem o quadro conceitual de uma Consciência Bioética (em Pereira Jr., 2013a);

c) O Monismo de Triplo Aspecto (MTA; Pereira Jr., 2013b) enquanto teoria filosófica sobre a evolução cosmológica, integrando os três aspectos considerados fundamentais de uma realidade unitária (a saber, os aspectos matéria/energia, forma/informação e sentimento/consciência). O MTA oferece critérios para discernimento de usos adequados e inadequados da tecnologia, e indica a necessidade de entrelaçamento de aspectos cognitivos e afetivos na busca por condutas que favoreçam a sustentabilidade.

\section{BASES TEÓRICAS}

A Ética da Sustentabilidade, como se pode visualizar no diagrama de Smookler (reproduzido acima), se ancora em uma concepção teórica de unidade na diversidade, assumindo que eventos que ocorrem em várias esferas da vida humana e do ambiente se relacionam, formando um sistema cuja dinâmica vem a determinar os caminhos evolutivos. Nesta perspectiva, um sistema sustentável seria um sistema humano/social auto-organizado, ou seja, um sistema que:

a) Disponha da capacidade de se manter em estados globais de organização econômicosocial que sejam estáveis, às custas de trocas de energia, matéria e informação com o ambiente;

b) Defina seus rumos por meio de padrões interativos que envolvam relações de todos os agentes com todos, ou seja, por meio de uma organização econômica-social democrática.

Neste contexto, assumimos que uma organização não democrática impossibilite a autoorganização econômica-social, vindo a caracterizar um padrão no qual predomina a heteroorganização, no sentido de Debrun (1996). Há hetero-organização em um sistema quando o mesmo é guiado por agentes externos, ou por um agente interno que estabeleça uma hierarquia linear, impossibilitando que os rumos do sistema sejam definidos pela interação de todos os agentes com todos. Na Figura 2, comparamos o atual sistema de democracia representativa com o sistema desejável, na perspectiva da auto-organização. 


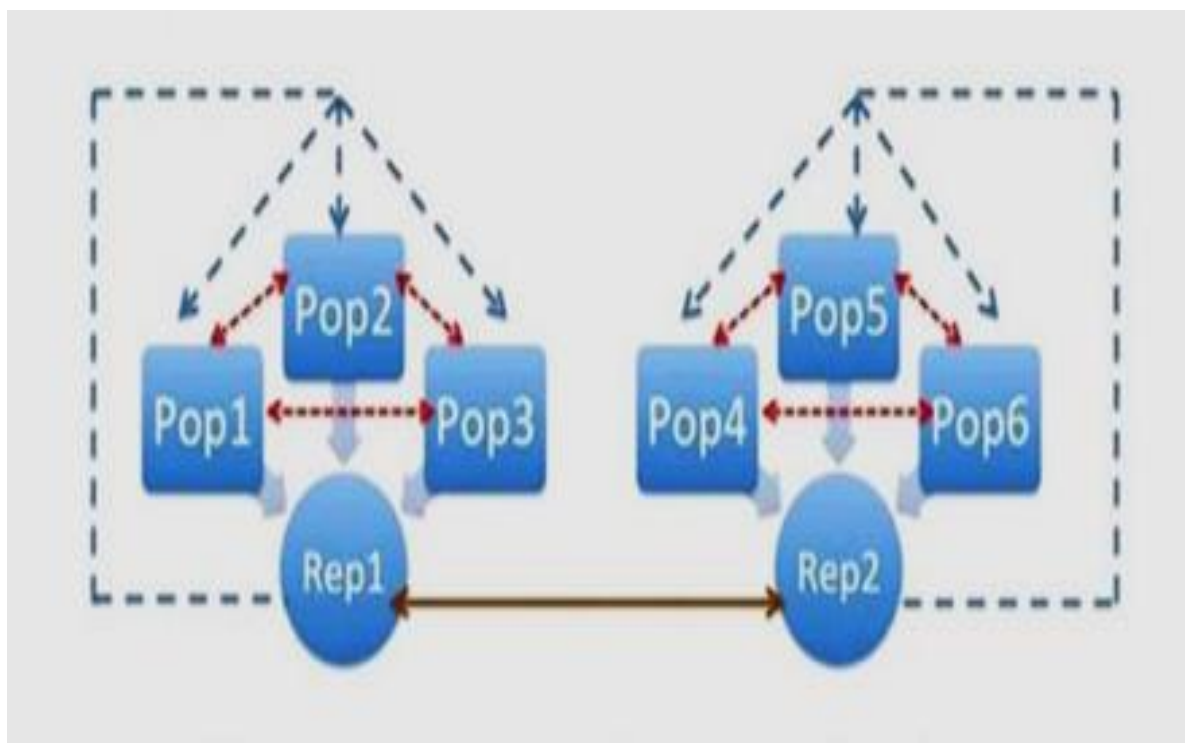

Figura 2: Auto-Organização e Democracia ${ }^{1}$.

Fonte: (vide Pereira Jr. et al., 2014).

A existência de liberdade é considerada como condição necessária para que as pessoas possam agir autonomamente (como argumentado, por exemplo, em Steiner, 2008), porém a experiência história tem mostrado que a liberdade e a autonomia não são suficientes para que a humanidade caminhe em direção à meta da sustentabilidade. Qual seria o ingrediente adicional que possibilitaria à população conquistar, por meio de suas próprias ações, uma qualidade de vida satisfatória?

Além da democracia, parece ser preciso desenvolver competências científicas e ações tecnológicas que possibilitem a efetiva solução de problemas que prejudicam a qualidade de vida. Entretanto, no contexto contemporâneo o papel da tecnologia é ambíguo: o progresso tecnológico tanto pode favorecer quanto desfavorecer a auto-organização popular (Pereira Jr., 2012); além disso, o tipo de tecnologia que é desenvolvida tanto pode favorecer quanto desfavorecer a sustentabilidade. Para enfrentar este problema filosófico, propomos o conceito de Consciência Bioética, que é apresentado na próxima seção.

\footnotetext{
${ }^{1} \mathrm{Na}$ democracia representativa, os eleitos (Rep 1,2 na figura) interagem entre si, no Parlamento (seta marrom), mas as pessoas $(\boldsymbol{P o p} 1, \ldots, \boldsymbol{\sigma})$ não necessariamente interagem entre si. Para que a auto-organização popular possa existir, além do contato "vertical" (retorno dos eleitos às suas bases eleitorais para discutir as propostas que apresentam no Parlamento; setas azuis), também é preciso desenvolver mecanismos para que as pessoas discutam e decidam coletivamente a respeito dos principais problemas que as afligem (setas vermelhas). Até o surgimento da Internet, esta interação "horizontal" só era possível para pequenos grupos, como no caso da cidade-estado grega na antiguidade. Hoje em dia já é possível pensar em um Fórum Oficial em que grupos organizados da população possam discutir problemas nacionais e internacionais, controlar a atividade dos eleitos e da máquina estatal, e até votar questões de grande interesse, eventualmente vindo a substituir partes do Parlamento.
} 


\section{CONSCIÊNCIA BIOÉTICA E SUSTENTABILIDADE}

A Bioética se afirmou nos últimos anos como disciplina deontológica voltada para a regulação de relações humanas no âmbito da prática profissional em saúde, e da pesquisa com seres humanos e animais. Seu caráter filosófico se expressa na formulação de princípios de conduta (a saber, princípios da Autonomia, Beneficência, Não-Maleficiência e Justiça; para uma revisão de trabalhos clássicos na área, vide Kuhse e Singer, 2000).

$\mathrm{O}$ alcance prático da Bioética tem mostrado a importância da conduta profissional justificada por princípios filosóficos, mas ao mesmo tempo tem revelado os limites destes princípios, frente à complexidade das questões éticas que emergem na vida humana. Para alargar o escopo filosófico da Bioética, Hossne (2008, 2009a, 2009b) tem desenvolvido uma dupla estratégia, promovendo a criação de mecanismos práticos de atuação profissional na área de saúde e desenvolvendo uma linha de pensamento original, no sentido da formulação de referenciais filosóficos que embasem o pensamento bioético frente à complexidade da existência humana no contexto sócio-histórico contemporâneo.

A Ética da Sustentabilidade sugere um novo passo para o desenvolvimento filosófico da Bioética, que seria sua extensão para o âmbito de uma Ética da Vida, incluindo questões ambientais, sociais e tecnológicas, promovendo a formação de uma consciência planetária (Axelos, 1969; Singer, 2002), que visa a identificação das condições que possibilitam a vida humana com qualidade em nosso planeta, e das consequências de ações humanas - em particular, daquelas advindas dos progressos biotecnocientíficos (Lacey, 1998; 1999; 2001) no sistema planetário, favorecendo ou desfavorecendo o processo da vida.

Nesta perspectiva, o âmbito de estudos da Bioética se estenderia para além da área de Saúde, se voltando para a formação da Consciência Bioética, enfocando as relações entre natureza, ciência, tecnologia e sociedade, se preocupando com as condições de vida e saúde de pessoas, animais e seus ambientes, e se tornando inseparável do âmbito educativo no cuidado com os rumos e destinos da espécie humana. Hossne (comunicação pessoal, 2014) considera que suas pesquisas sobre referenciais filosóficos da bioética conduzem ao conceito de Consciência Bioética, com a abrangência que lhe atribuímos.

\section{O PAPEL DA CONSCIÊNCIA NO PROCESSO EVOLUTIVO}

James Mark Baldwin (Baldwin, 1896) talvez tenha sido o primeiro pensador a defender explicitamente um papel da consciência no processo evolutivo darwiniano. Ao optar por uma 
ação que produza uma reação prazerosa, ao invés de uma ação que produza uma reação dolorosa (e deste modo contribuindo para gerar um novo hábito que venha a influenciar os padrões de reprodução de uma população), todo ser consciente estaria participando na definição dos rumos do processo evolutivo. Essa proposta teria uma consequência importante para a Bioética, no sentido amplo de Ética da Vida: ao realizar suas opções conscientes, todo sistema vivo influencia os rumos do processo evolutivo. Entretanto, uma consciência bioética pressupõe mais que escolhas hedônicas; é preciso que hábitos assim formados embasem ações intencionais voltadas a metas admiráveis, o que Aristóteles entendia como sendo a virtude da magnanimidade.

Como a atividade consciente influenciaria o processo evolutivo? Segundo Baldwin (1896), “a função principal da consciência é possibilitar...aprender coisas que a hereditariedade natural não consegue transmitir...O princípio do Hábito deve ser reconhecido de algum modo geral, que permitirá ao organismo fazer coisas novas sem desfazer totalmente o que já adquiriu" (Baldwin, 1896, p. 302, trad. APJ). Entretanto, tais inovações não poderiam ocorrer ao acaso; Baldwin se perguntava: "estímulos do meio ambiente podem produzir novos movimentos adaptativos...de variações de movimento;...Como essas variações de movimento são produzidas quando e onde elas são necessárias?...Como o organismo mantém esses movimentos que são assim selecionados, e suprime aqueles que não estão selecionados?” (Baldwin, 1896, p. 303, trad. APJ).

As experiências conscientes, marcadas pelo prazer e pela dor, induzem um processo auto-organizativo do sistema vivo, pelo qual novos hábitos são formados no plano ontogenético, podendo vir a influenciar a dinâmica filogenética: “A função do prazer e da dor é apenas manter algumas ações ou movimentos e suprimir os outros... Ações que assegurem condições agradáveis ao organismo são determinadas pelo prazer a ser repetido, e assim assegurar a continuação das condições prazerosas; e ações que levam o organismo à dor são pelo próprio fato da dor suprimida...(O sistema vivo) distingue em sua forma e quantidade entre estímulos que são vitalmente bons e aqueles que são vitalmente ruins...O termo "circular" é usado para enfatizar o modo como tal reação tende a se manter, repetidamente, reproduzindo as condições de sua própria estimulação" (Baldwin, 1896, p. 303-4, trad. APJ).

Recusando a interpretação Neo-Lamarckista da transmissão filogenética dos hábitos ontogenéticos, Baldwin entende que a herança destes traços se daria por meio social ("herança social", cf. Baldwin, 1896, p. 305), idéia que veio a constituir o (atualmente chamado) "Efeito 
Baldwiniano" (vide, por exemplo, Deacon, 1996).

\section{CONSCIÊNCIA BIOÉTICA E O MONISMO DE TRIPLO ASPECTO}

O papel da Consciência Bioética no processo evolutivo pode ser abordado a partir do Monismo de Triplo Aspecto (MTA; Pereira Jr., 2013b). O MTA procura desenvolver uma ontologia interdisciplinar, utilizando conceitos oriundos das diversas ciências (naturais, formais, humanas) e filosofia. A realidade se constituiria como processo (Whitehead, 1929) que se desdobra em três aspectos irredutíveis e inter-relacionados: o aspecto físico-químico-biológico, o aspecto formal/informacional (que compõe processos cognitivos não conscientes) e o aspecto mental consciente, caracterizado pela presença do sentir. Neste processo temporal, as possibilidades naturais se atualizam progressivamente, inicialmente pelo aspecto físico, em seguida pelo aspecto mental não-consciente e então, onde e quando as condições necessárias se apresentam, no aspecto mental consciente (Figura 3).

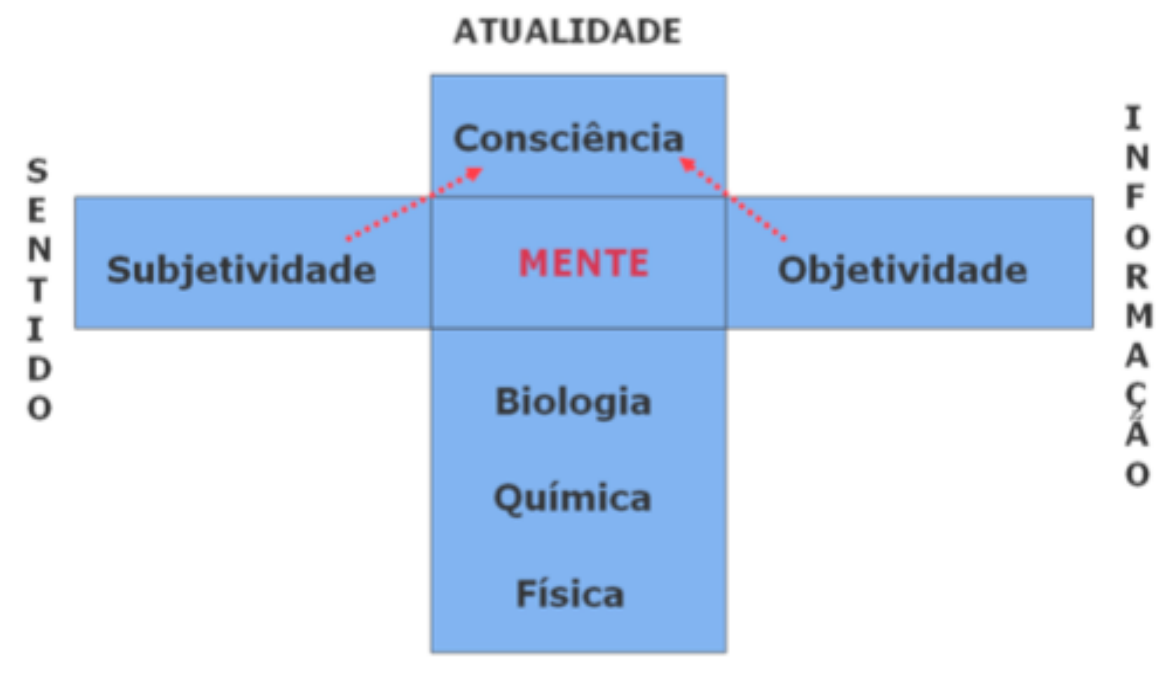

\section{POSSIBILIDADE}

Figura 3: Monismo de Triplo Aspecto.

Fonte: setas vermelhas na figura, constituindo a estrutura dual proposta por Husserl (1913).

O MTA é uma ontologia interdisciplinar, que procura construir um conceito de realidade a partir de conceitos utilizados nas ciências, incluindo as ciências formais e humanas. A Natureza é concebida pelo MTA, seguindo a sugestão de Aristóteles (vide discussão em Pereira Jr., 2013b), como conjunto de possibilidades, atualizadas ou não ao longo do tempo. O processo evolutivo é concebido como progressiva passagem de potencialidades para atualidades (processo "de baixo para cima" na figura), começando no domínio estudado pelas ciências 
físicas, e progredindo nos domínios da química, biologia, ciências da forma e da informação, e culminando com a ciência da consciência, que se baseia no tripé: Fenomenologia (estudo das experiências na perspectiva de primeira pessoa)-Ciências do Cérebro-Ciências do Comportamento. Já no âmbito dos processos informacionais nos sistemas vivos, pode-se notar a distinção do domínio subjetivo - do significado da informação para o sistema - e um domínio objetivo - dos processos de transmissão de informação, quantificados por meios digitais, que constituem parte de nosso ambiente tecnológico (figura originalmente publicada em Pereira Jr., 2013b). Esta distinção subjetivo-objetivo se reproduz na estrutura interna da consciência (vide setas vermelhas na figura), constituindo a estrutura dual proposta por Husserl (1913).

A consciência teria uma estrutura dual, ou seja, um polo subjetivo e um polo objetivo, como proposto originalmente por Husserl (1913). Note-se que usamos aqui uma abordagem naturalista, muito diferente da filosofia husserliana, retendo deste autor apenas o esquema da estrutura da consciência. Devido à propriedade mental intitulada intensionalidade da consciência, o pólo subjetivo (o Eu consciente) tematiza um conteúdo objetivo (um episódio, composto por padrões informacionais processados no cérebro). Em acréscimo ao modelo de estrutura da consciência husserliano, o MTA sugere que a experiência de um determinado conteúdo objetivado afeta o Eu consciente, gerando um sentimento (vide o processo mental ilustrado na Figura 4). Um sentimento, neste sentido, seria um estado do pólo subjetivo (Eu consciente) resultante da experiência de um determinado conteúdo objetivo. Na figura abaixo o Eu consciente intensionalmente tematiza um determinado conteúdo objetivo, que é recortado no espaço e no tempo como sendo um episódio integrado. Sua interação com tal episódio produz uma experiência consciente, um processo dinâmico que concomitantemente afeta o Eu, despertando os sentimentos.

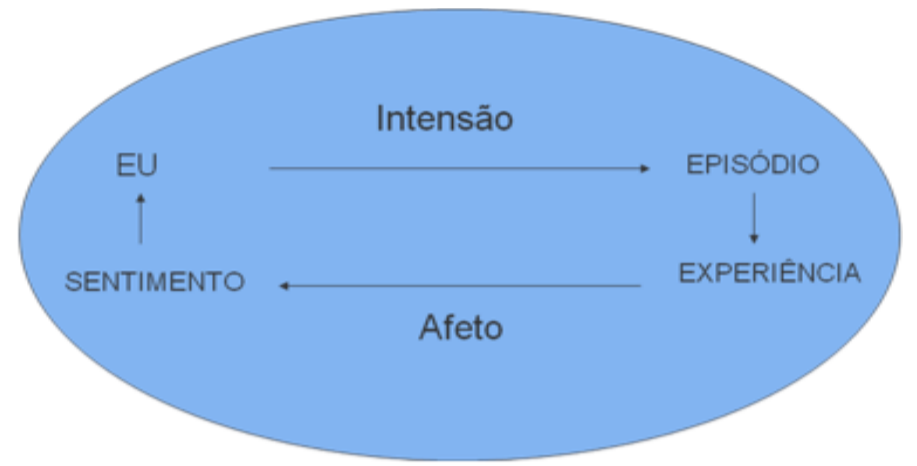

Figura 4: Formação de Hábitos Sentimentais.

Fonte: (vide Pereira Jr. et al., 2013). 


\section{A FORMAÇÃO DA CONSCIÊNCIA BIOÉTICA}

Os hábitos sentimentais constituídos na história de vida de uma pessoa vêm a compor sua identidade, a qual constitui o referencial em relação a qual suas atitudes éticas são estabelecidas. Considera-se aqui que uma atitude ou ação meramente reativa, reprodutora de hábitos disseminados em uma determinada cultura, constitua um comportamento moral. Uma consciência ética pressupõe mais que a moralidade, pois incorpora a possibilidade de se agir contrariamente aos hábitos disseminados em uma sociedade; ou seja, no caso do comportamento moral o "dever ser" (meta da ação) se reduz ao "ser" (estados de coisas dado em determinado contexto sócio-histórico), enquanto no caso de uma ação conduzida pela consciência ética haveria uma tensão entre o "ser" e o "dever ser", que podem não coincidir, fazendo com que o agente ético enfrente dificuldades e obstáculos para atingir uma meta que reflita ou simbolize sua identidade pessoal. Esta tensão nos leva a colocar em questão propostas éticas pragmatistas na linha de Singer (1979).

O processo de formação da consciência ética é ilustrado no diagrama da Figura 5. Este pressupõe uma intencionalidade, distinta da intensionalidade anteriormente mencionada, pois enquanto a intensionalidade constitui uma operação mental de se tematizar (na linguagem fenomenológica) ou enfocar a atenção (na linguagem da neurociência cognitiva) um determinado conteúdo mental, a intencionalidade consiste em uma disposição de direcionar a ação para uma determinada meta que é posta intensionalmente. Tal meta não se encontra realizada no estado de coisas atual do agente, mas é concebida como um estado que deveria ser realizado, de acordo com o referencial construído em sua história de vida.

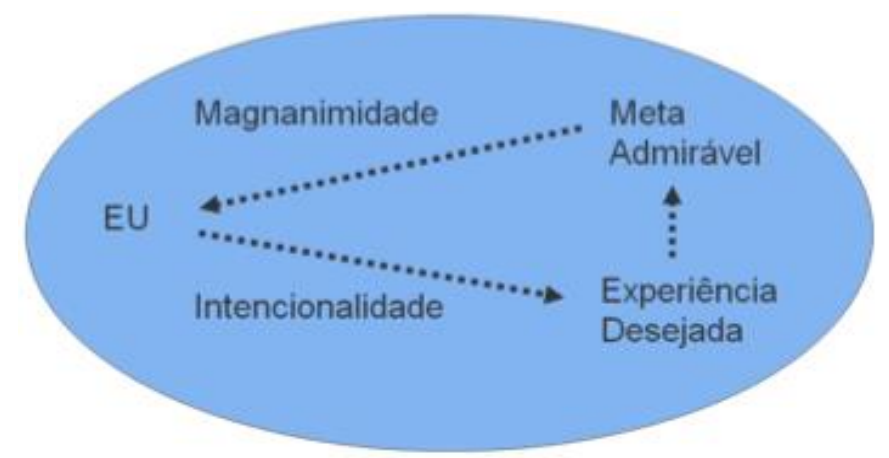

Figura 5: Formação da Consciência Ética. Fonte: (vide Pereira Jr. et al., 2013).

$\mathrm{Na}$ figura acima, o Eu consciente projeta no tempo uma experiência objeto de seu desejo, a qual 
implica uma meta admirável (esteticamente bela, conforme o referencial do sujeito) a ser alcançada. A concepção desta meta, e a ação em conformidade com ela, propiciam uma condição subjetiva vivenciada como autenticidade, sabedoria e/ou plenitude de sentido. Tomado por esta condição, o agente ético pode enfrentar desafios, superar dificuldades e enfrentar obstáculos que se interponham entre seu estado atual e o estado de coisas desejado.

Ao longo de sua história de vida, um sistema consciente constitui hábitos hedônicos. Os hábitos interiorizados no $\mathrm{Eu}$ guiam sua conduta intencional, em busca de experiências desejadas. No caso da sustentabilidade, torna-se necessário que a projeção de metas admiráveis enseje a Consciência Bioética, pela qual o agente transcenda o hedonismo imediato, enfocando as relações sistêmicas que determinam a qualidade de sua vida, e enfrentando condições adversas para atingir a meta da sustentabilidade. Neste sentido, a sustentabilidade requer a magnanimidade, o que se traduziria na época contemporânea na renúncia aos ideais consumistas e na busca por novos modelos de relações econômicas, sociais e ambientais.

\section{CONSIDERAÇÕES FINAIS}

A Consciência Bioética, resultante de processos filo/ontogenéticos, participa da determinação dos rumos do processo evolutivo, em direção a uma maior sustentabilidade, a partir da formação de novos hábitos sentimentais (no sentido da expressão acima definido). Portanto, a ancoragem da Ética da Sustentabilidade se daria no plano afetivo, na motivação de novas condutas, o que implica na necessidade de implantação de programas educativos neste sentido. Os processos cognitivos e as ações sociais (incluindo o desenvolvimento de novas tecnologias), em busca da sustentabilidade, dependeriam do estabelecimento destes novos hábitos.

Para o MTA o progresso tecnológico não necessariamente reforçaria a tendência ao “esquecimento do ser” sugerida pela filosofia de Martin Heidegger e seus sucessores (na área de saúde, destaca-se o trabalho de Gadamer, 2006), mas constitui uma oportunidade de manifestação de potencialidades. Por exemplo, o laser (estado coerente da luz) é uma potencialidade que permanecia latente até o momento em que - por meio de recursos tecnológicos - veio a ser atualizada e aplicada em produtos tecnológicos, se tornando uma ferramenta útil para a experiência de vida humana. Do mesmo modo, drogas e medicamentos, como os anti-depressivos (inibidores da recaptura da serotonina), conduzem o sistema nervoso a estados de menor sofrimento que este sistema poderia não atingir espontaneamente. 
O MTA aponta para diretrizes éticas que se diferenciam das propostas dos críticos ferrenhos da tecnologia. A tecnologia deixa de ser vista como algo intrinsecamente alienante, e passa a ser justificada como meio de atualização de potencialidades da natureza. Assume-se uma continuidade entre natureza e cultura, de modo que as realizações culturais são concebidas como atualizações de potencialidades da natureza.

Nesta perspectiva, deve-se avaliar os produtos tecnológicos em termos de custobenefício. Haveria uma relação entre o caráter auto-organizativo dos processos sociais geradores da inovação tecnológica e seus benefícios para a maioria da população. A alienação humana, por sua vez, se correlacionaria com processos sociais de inovação tecnológica heteroorganizados, ou seja, processos em que a tecnologia é utilizada como meio de exploração econômica, dominação político-militar e/ou controle ideológico de uma maioria por uma minoria (como discutido em Pereira Jr., 2012).

Agradecimentos a FAPESP e colegas do grupo de pesquisas sobre Auto-Organização (UNICAMP). Dedico esse ensaio à memória do Prof. Dr. William Saad Hossne (UNESPBotucatu), principal propulsor da Consciência Bioética no Brasil.

\section{REFERÊNCIAS BIBLIOGRÁFICAS}

Aristóteles. The Complete Aristotle. Adelaide, Australia: Feedbooks, 2012. Disponível em: www.feedbooks.com/book/4960/thecomplete-aristotle.

Axelos, K. O Planetário. A História do Mundo da Técnica. Em: Axelos K. (Org.) Introdução ao Pensamento Futuro. Rio de Janeiro: Tempo Brasileiro, 1969.

Baldwin, J.M. Consciousness and Evolution. Psychological Review 3(3), 300-309, 1896.

Bresciani Filho E. e D'Ottaviano I.M.L.Conceitos Básicos de Sistêmica.

Em: Auto-Organização: Estudos Interdisciplinares. Coleção CLE 30, Campinas: UNICAMP, p. 283-306, 2000.

Deacon, T.W. The Symbolic Species: The Co-Evolution of Language and the Brain. New York: W.W. Norton and Co, 1997.

Debrun, M. A Idéia de Auto-Organização.
In: Debrun, M., Gonzales, M.E.Q., Pessoa Jr, O. (Orgs.) Auto-Organização: Estudos Interdisciplinares. Campinas: CLE/UNICAMP (Coleção CLE. Vol. 18), p. 3-23, 1996.

Gadamer, H.G. (2006) O Caráter Oculto da Saúde. Trad. de Antônio Luz Costa. Petrópolis: Vozes; 2006.

Hossne WS. Bioética - Princípios ou Referenciais. Mundo da Saúde 30: 673-6, 2006.

Hossne WS. Dos referenciais da Bioética A Prudência. Rev Bioethikos 2: 185-96, 2008.

Hossne WS. Dos referenciais da Bioética A Vulnerabilidade. Rev Bioethikos 3: 4151, 2009.

Hossne WS. Dos referenciais da Bioética A Equidade. Rev Bioethikos 3(2): 211-216, 


\section{9.}

Husserl E. Ideas: General Introduction to Pure Phenomenology. F. Dordrecht: Kluwer Academic, 1983.

Jennings, B. Ethical Aspects of Sustainability. 2010. Disponível em: http://www.humansandnature.org/filebin/p df/minding_nature/April_2010_Ethical_As pects_of_Sustainability.pdf

Kibert C.J., Thiele J., Peterson A. and Monroe M. The Ethics of Sustainability, 2014. Disponível em: http://www.cce.ufl.edu/wpcontent/uploads/2012/08/Ethics\%20of\%20 Sustainability\%20Textbook.pdf

Kuhse, H. and Singer, P. Bioethics: An Anthology. Oxford: Blackwell Publishers, 2000.

Lacey, H. Valores e Atividade científica. São Paulo: Discurso Editorial, 1998.

Lacey, H. Is science value-free? Values and Scientific Understanding. Londres: Routledge, 1999.

Lacey, H. A Tecnociência e os Valores do Fórum Social Mundial. Em: Loureiro, I., Leite, J.C. e Cevasco, M. (Orgs.) $O$ Espírito de Porto Alegre. São Paulo: Paz e Terra, 2001.

Morris, M. The Ethics of Sustainability. 2009. Disponível em: http://www.ilsr.org/presentation-ethicssustainability

Pereira Jr, A. Do Demiurgo ao Hacker: Tecnologia e Auto-Organização. Perspectivas em Ciências Tecnológicas v.1, p. $8-21,2012$.

Pereira Jr, A. Uma Concepção de Bioética na Perspectiva Evolucionista. SimbioLogias 6 (8): 62-67, 2013.

Pereira Jr, A. Triple-Aspect Monism: A
Framework for the Science of Consciousness. In: The Unity of Mind, Brain and World: Current Perspectives on a Science of Consciousness. Alfredo Pereira Júnior and Dietrich Lehmann (Eds.) Cambridge/ UK: Cambridge University Press Pereira Jr, A; Ilario, E.; Paixão, V.G.; Chinali, L. A.; Monserrat 2013.

Neto J. Tecnologia, Democracia e Socialismo: o Encontro do Século? Perspectivas em Ciências Tecnológicas 3: 88-108, 2014.

Singer, P. Practical Ethics. Cambridge: Cambridge University Press, 1979.

Singer, P. One World: The Ethics of Globalization. New Haven: Yale University Press, 2002.

Thompson, P.B. Sustainability: Ethical Foundations. Nature Education Knowledge 3(10):11, 2012. Disponível em: http://www.humansandnature.org/filebin/p df/minding_nature/April_2010_Ethical_As pects_of_Sustainability.pdf

Seager, T.P. Sustainability Ethics: Experiential Approaches to Moral Complexity. 2013. Disponível em: http://sustainabilityethics.com/

Smookler, H.B. Sustainability Ethics. $2010 . \quad$ Disponível em: http://pt.slideshare.net/uclaextensionppp/su stainability-ethics-course

Steiner, R. A Filosofia da Liberdade Fundamentos para uma Filosofia Moderna. 4a . Edição. São Paulo: Ed. Antroposófica, 2008.

Whitehead A.N. Process and Reality: An Essay in Cosmology. Gifford Lectures delivered in the University of Edinburgh during the session 1927-1928. New York: Macmillan e Cambridge UK: Cambridge University Press, 1929. 
JUNIOR, A. P.; JUNIOR, V.G.P. Auto-Organização e Bioética: O Problema da

Sustentabilidade. Complexitas - Rev. Fil. Tem. Belém, v. 2, n. 2, p. 43-57, jul./dec. 2017. Disponível em:<http://www.periodicos.ufpa.br/index.php/complexitas/article/view/6597>. Acesso em: 07 de janeiro de 2019. 